\title{
A Review on Micro Formings
}

\author{
Amin Teyfouri ${ }^{1}$, Milad Ahmadi ${ }^{1}$, Erfan Shamsaddini lori $^{1} \&$ Shahryar Sorooshian ${ }^{2}$ \\ ${ }^{1}$ Department of Mechanical and Manufacturing Engineering, Faculty of Engineering, Universiti Putra Malaysia, \\ Malaysia \\ ${ }^{2}$ Faculty of Industrial Management, Universiti Malaysia Pahang, Malaysia \\ Correspondence: Amin Teyfouri, Department of Mechanical and Manufacturing Engineering, Faculty of \\ Engineering, Universiti Putra Malaysia, Malaysia. E-mail: amin.teyfouri@yahoo.com
}

Received: June 7, $2014 \quad$ Accepted: June 12, $2015 \quad$ Online Published: August 30, 2015

doi:10.5539/mas.v9n9p230 URL: http://dx.doi.org/10.5539/mas.v9n9p230

\begin{abstract}
Nowadays, there are increasing demand on micro-systems, micro products/components and micro-devices. Thus, the role of micro manufacturing in all aspects of modern industry is taken for granted. Then, typical processes in micro manufacturing are discussed. Furthermore, one of the most widespread micro-manufacturing processes in deforming processes is micro forming that is presented in this paper. Finally, besides continuing effort in developing micro forming, this paper strives to analyze systematically the key methods of stamping, bending, forging and deep drawing processes and their prominent issues.
\end{abstract}

Keywords: Micro-manufacturing, Micro-forming, Micro stamping, Micro forging, Micro bending, Micro deep drawing

\section{Introduction}

Presently, pluralities of industrial developments are made for compact products. Dramatic changes in during two decades in economic and science, have influenced how manufacturing is organized and implemented. The trend toward using micro-scale products for biomedical, electronics, aerospace and defense has been soaring throughout the world. As a matter of fact, Micro-manufacturing engineering is a series of relevant activities within the chain of manufacturing micro-products/features, involving design, analysis, materials, processes, tools, machinery, operational management methods and systems, etc. For product in measure of nanometer and micrometer range, it is no longer trivial to describe how these component are measured, created, handled, assembled and controlled. If micro- products are presented by a huge market it is vital to develop production technology, processes and material that have ability for supporting an industrial production; that is, as Masuzawa mentioned at progression of technology in micro scale, industry has to consider on modern technology in production chain of micro product (T.Masuzawa, 2000) Figure 1. Undoubtedly, a common micro-manufacturing structure is micro forming process; that is, it is widely used in deforming processes for the mass-manufacture of micro-products.

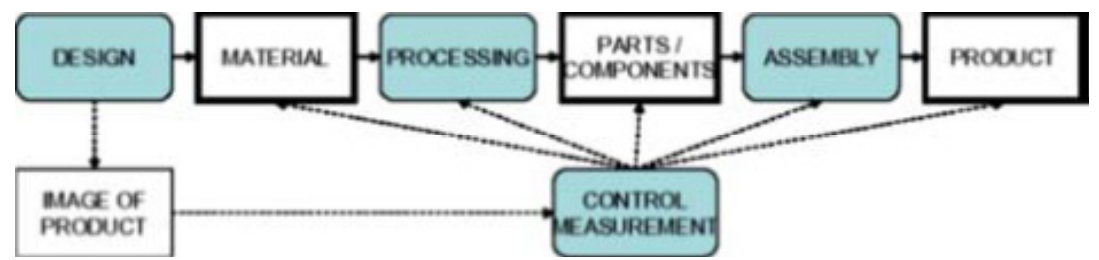

Figure 1. Association between objects in the process chain of production and technologies (T.Masuzawa, 2000)

The forming of miniature-parts or small metal-parts has been evaluated for long time but when sizes decrease to hundreds of microns, precision requirements for small-parts reduce to less than a few microns. Thus, forming of micro scale is required to day-to-day investigation. This paper provides an overview of the approaches perform for the micro-forming method Figure 2. 


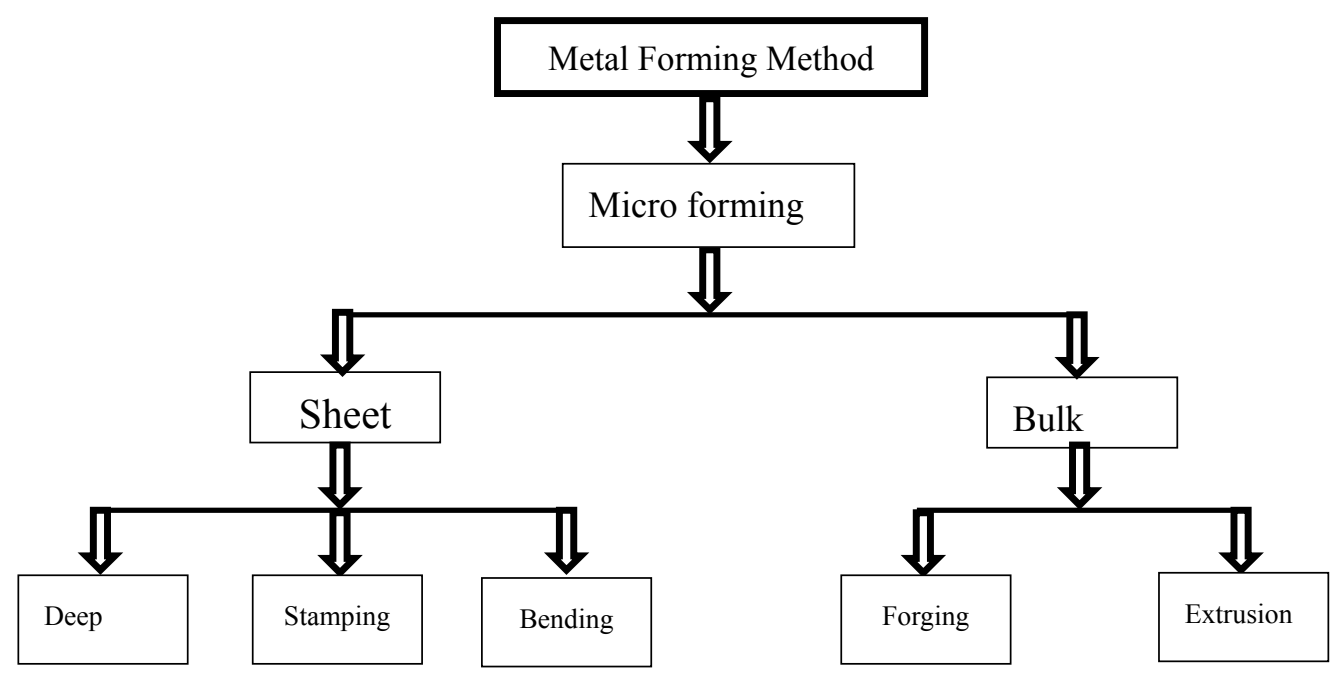

Figure 2. The approaches of micro-forming method

Obviously, conventional and non-conventional approaches have been widely utilized to manufacture micro-products by miniaturizing or downscaling (Aldo Attanasio, 2013). In fact, general manufacturing processes can be categorized to subtractive, joining, hybrid and deforming processes in table 1 (Qin, 2010). The most substantial advantage of micro-manufacturing is the capability for producing parts which having feature

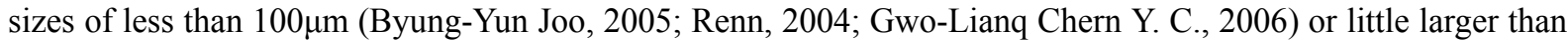
the thickness of a human hair.

Table 1. Processes in micro-manufacturing (Qin, 2010)

\begin{tabular}{|c|c|}
\hline $\begin{array}{l}\text { Subtractive } \\
\text { processes }\end{array}$ & $\begin{array}{l}\text { Micro-Mechanical Cutting (polishing, grinding, turning, milling, } \\
\text { etc.), Photo-chemical-machining, Laser Beam Machining, Electro } \\
\text { Beam Machining. }\end{array}$ \\
\hline $\begin{array}{l}\text { Joining } \\
\text { processes }\end{array}$ & $\begin{array}{l}\text { Micro-Mechanical-Assembly, Gluing, Resistance, Bonding, } \\
\text { Laser-welding, Vacuum Soldering, laser, etc. }\end{array}$ \\
\hline $\begin{array}{l}\text { Hybrid } \\
\text { processes }\end{array}$ & $\begin{array}{l}\text { Micro-Laser-ECM, Micro-EDM and Micro-ECM and Laser } \\
\text { assembly, Combined micro-machining and casting, } \\
\text { Laser-assisted-micro-forming, Shape Deposition and Laser } \\
\text { machining, LIGA and LIGA combined with Laser-machining, } \\
\text { Micro assembly injection moulding, etc }\end{array}$ \\
\hline $\begin{array}{l}\text { Deforming } \\
\text { processes }\end{array}$ & $\begin{array}{l}\text { Micro-forming (stamping, bending, deep drawing, forging, } \\
\text { extrusion, hydro-forming, incremental forming, superplastic } \\
\text { forming, etc. Hotembossing, Micro/Nano-imprinting, etc. }\end{array}$ \\
\hline
\end{tabular}

Micro-mechanical cutting is a fabrication procedure for producing miniature devices and components with feature of tens of micrometers to a little millimeter in size. The motivation for micro-mechanical cutting stem from the translation of macro-process knowledge to the micro-domain (J. Chae, 2006). Precision cutting tools are so important due to feature and quality of micro-structures. The majority of micro-machine tools are created from ultra-precision material as well as high rigidity. Even though this approach have been encountered with some challenging problems such as producibility, predictability, and productivity (Xichun Luoa, 2005). Recent researches demonstrate use of cutting force in micro-machining can help to improve and monitoring the quality of sculptured products (X Liu, 2004) in addition industrialized analytical cutting force model aid operators to select the right cutting condition for their organization or system. Furthermore, the elastic-plastic deformation of the work piece also changes the cutting force in micro-machine operations. Typical micro-cutting operations 
include micro-milling, micro-turning, micro-drilling and micro-grinding.

Micro-mechanical assembly is an approach for assembling components on micro-scales, where the relative location of components is kept by exchange of contact forces providing by mechanical limitation. Main processes for micro-assembly and packaging involve micro-casting/moulding, micro-welding, mechanical placement/insertion/ pressing, resistance/laser/vacuum soldering, bonding, gluing, etc. Interconnection and packaging solutions are a vital technology for connecting micro-systems to the macro world (Yi Qin A. B., 2010). The base of mechanical assembly is classified to three purposes of handling and positioning with the function of setting two or more items into specific mutual position and orientation, mechanical assembly with the goal of ensuring the mutual connection between components against outside properties and quality control for ascertaining whether the mechanical assembly process has been carried out as specified (Hans Nørgaard Hansen, 2010). Obviously, the both general domain of automated and manually assembly of micro devices include handling of parts that are extremely small (in the order of $10^{-6} \mathrm{~m}$ ).

Moreover, they take into account increase of reliability, efficiency as well as reducing cost (J. Cecil, 2007). Even though substantial progress has been created in the manufacture of individual micro components/parts, there is still a major amount of manual work included in assembly/packaging of the micro-products and systems. There are prominent issues in micro-assembly such as lack of the guidelines and the requirements for tailor-made tools for the processes.

Micro-machining technology has an exclusive opportunity to produce micro-components that are so flexible and cost-effective and it is noted that recognition correct method in machining has significant role in preventing defect specially in micro scale; i.e., some types of method such as contact measurement is not suitable for micro fabrication since the structure of micro parts are low rigidities however this method is the most certain method to change the shape of work piece. Incontrovertibly, optical technique is appropriate for quantitative measurement (Nagayoshi Kasashima, 2012); for instance, accenting laser micro machining of up to $1 \mathrm{~mm}$ thick metal should consider on advanced performance. In laser's characteristics such as pressure, the movement of optics and piece, laser beam alignment, temperature, energy distribution, combination of pulse with wavelength for penetration depth and providing optical and other characteristics must be optimized for development of a laser processing scheme in micro-machining (D. Jahns, 2013).Moreover, Electrical machining is special method in micro technology such as micro-electrical discharge machining (EDM) and micro-electrochemical machining (ECM). In ECM and EDM, the main goal is to forecast the shape of the workpiece. EDM with the famous title of laser drilling is basically a thermal process and consequently thermal modeling is so imperative while ECM computes the work dissolution rate with function of determination of the current density distribution (S. Hinduja, 2013).

\section{Micro Forming Methods}

Micro-products often are introduced by process of plastic forming technology (Qin, Micro-forming and miniature manufacturing systems - development needs and perspectives, 2006).Various process in microforming method is included stamping, forging, hydro-extrusion, extrusion, bending, superplastic forming, deep drawing, etc. These processes is implemented by real scaling down of the conventional structures, tools and machines with additional maintenances (K.P. Rajurkar, 2006). Micro-forming can be one of the best options in the mass-manufacture of micro-parts, where the micro-forming machine is autonomous and it is integrated with parts transport systems and high precision feeding (Akhtar Razul Razali, 2013). In fact, quality and efficiency are two important part in handling devices, machines and forming tools in industrial application of micro-forming. Heating has been widely used for micro-forming process since it helps to higher strength or extend forming ability in terms of part and dimensions and it is really common in micro-forming process. Main problems has to be addressed in this method include qualification of forming limits, tool/material interfacial conditions, process design optimization, process modeling and analysis, understanding of material deformation mechanisms and material property characterization (Yi Qin A. B., 2010).

\subsection{Stamping and Sheet Metal Structure}

It is noted that stamping is a prominent method in forming process. Nowadays, Metal stamping manufacturing processes are popular because they are an economical and quick means of producing intricate, accurate, strong and durable articles in huge quantities (B.T. Cheok, 1998). In fact, metal stampings are used in most of the mass-produced product with different methods. According to a survey in the US, every American home has almost 100000 metal stamping process in the 1980s (Nee, 1989). Metal stamping has been entered in the manufacturing of metal components with a particular configuration from sheet metal stock and a various range of processes such as embossing, punching, flanging, blanking, coining, and bending (Kalpakjian S, 2006). Stamping can be done on metals such as titanium, bronze, aluminium, zinc, nickel, steel, Inconel, copper, and 
other alloys (Akhtar Razul Razali, 2013). Sheet metal components are used numerous applications such as aircraft, electronics products and for packaging such as consuming goods and computer screen etc. Sheet metal parts include electrical connectors and lead frames, micro-meshes for masks and optical devices, micro-springs for micro-switches, micro-cups for electron guns and micro-packaging, micro-laminates for micro-motor and fluidic devices, micro-gears for micro-mechanical devices, casings/housings for micro-device assembly/packaging, micro-knives for surgery, etc. Sheet metal, stamping are one of the most effective approaches to meet the future demand of mass production (Tsung-Chia Chen, 2013). Traditionally, sheet metals may be defined as metal having a thickness of between 0.4 and $6 \mathrm{~mm}$, while micro-sheet forming usually deals with sheet metals of which the thickness is usually below $0.3 \mathrm{~mm}$. Previous academic results show that stamping processes can be real in using thin metal in Bipolar plates that are one of the essential components of proton exchange membrane fuel cells (Toyoaki Matsuura, 2006; Jie Xu, 2011;Toyoaki Matsuura, 2006).

Micro stamping: It may indeed be true to say that micro-stamping is a target for producing miniaturized components and products. Micro-stamping is valuable for producing some components such as wristwatch and micro handheld-device components, medical products and so on (Kalpakjian S, 2006). Development of micro stamping in process have shown the effort for performing an automatic hybrid and simple punching operation on brass strips and continued movements in this development influence on manually-operated micro-stamping machine with the capability of employing various punch shapes and progression of micro stamping demonstrates the widespread use of this process in micro-sheet-forming (Gwo-Lianq Chern Y.-J. E.-F., 2006).

A micro-stamping test machine can be useful methods for progressive stamping chain, for example, dry micro-stamping machine designed to be hard enough in order to operate in down-sized configuration ,moreover, it has characterized to have maximum loading capacity up to $5 \mathrm{KN}$ as well as maximum 100rpm speed (Tatsuhiko Aizawa, 2007). As can be seen in Figure 3, progressive stamping chain in this test is collected of shearing, ironing and bending operations. Actually, the holes were punched out without substantial burrs in shearing process and the stage of ironing and bending might happen severe wear between worksheet and punch in ironed surface. The surface was evaluated by fine micrometer and optical microscope (Tatsuhiko Aizawa, 2007).

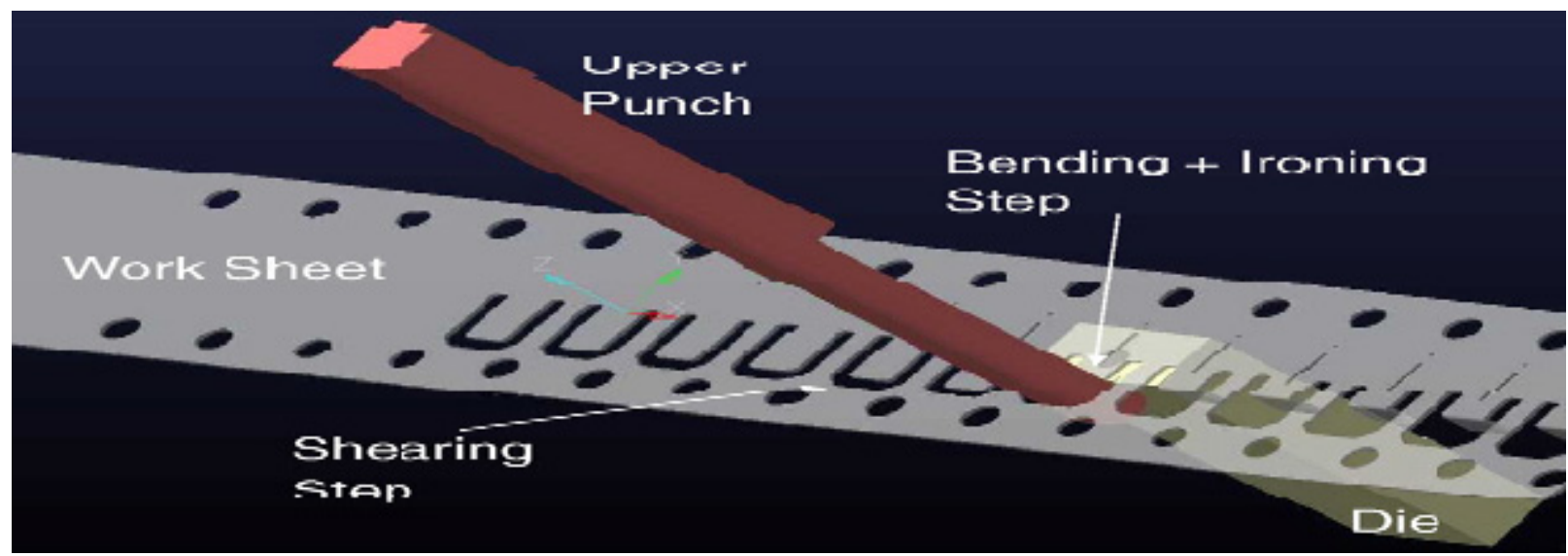

Figure 3. A micro-stamping test in the progressive stamping sequence (Tatsuhiko Aizawa, 2007)

Generally speaking, improvement of micro stamping needs to efforts to realize operation in terms of it process, tooling, and particularly material-handling. In addition, attention to micro material's sizes is a key point of stamping structure for modern manufacturing technology.

\subsection{Forging Structure}

Nowadays, forging methods are planned to being performed systematically in controlled presses and hammers to produce forged shapes with a high degree of dimensional accuracy and structural integrity. Statistics published by the Forging Industry Association show that forgings are used in $20 \%$ of all products that represent the U.S. Gross Domestic Product, and that the forging industry has annual sales of US\$ 6 billion and employs 45,000 personnel in North America alone (FIA, 1996). The forging industry is keeping pace as with other metal forming processes through continuous progress in many areas. Actually, six characteristics play important roles in forging process that include the development of alloys in processing or forgeability, growing the industry's understanding of the mechanics of the forging process as production rates ought to be increased, and costs reduced. The third 
characteristic is some forging companies have been using systems for controlling critical processes as reducing variables, improving dimensional precision, and eliminating costly chip-making operation. Using CAD $\backslash C A M$ throughout production processes and design to developing dimensional accuracy of forgings, forging companies should use modeling and forging simulation for minimizing development time. Finally, fast tool change capability facilitates the preplanned replacement of die inserts in long production runs, and reduces changeover time for shorter runs (http://www.forging.org/Design/page1.html, n.d.).

Forging process: Forging is probably oldest metal working process and was known even during prehistoric days when metallic tools were made by heating and hammering. Forging is basically involves plastic deformation of material between two dies to achieve desired configuration and depending upon complexity of the part forging is carried (Pandey, n.d.). Its noted that this process is particularly problematic as the high costs and long lead times is associated with die tooling represent serious obstacles to forging competitiveness (F.H. Osman, 1995) and another problem is the limit it places on product and design flexibility (Joseph Domblesky, 2006). As a matter of fact, the classification of modern forging process includes open die, impression die, ring rolling, warm forging and cold forging (http://www.forging.org/Design/page1.html, n.d.)

- Open die forging

Open die forging is hot forming process that usually worked for producing large parts. The shapes of open die forging usually are V-shape, semi-rounds, or flat. There is basically no limit to the size of a forging made with the open-die method. Nonetheless, most work will need extensive machining to achieve their shape or net shape. During the process of open die forging due to heavy duty and mechanical material handling, normally it is required to cranes, fork lifts, and rotating devices (http://www.forging.org/Design/page1.html, n.d.).

- Impression die forging

Utilizes a pair of matched dies with contoured impressions in each die. When the dies close, the impressions form a cavity in the shape of the forging. Often two or more progressive impressions are used, sometimes in conjunction with one or more preforming operations, to form the desired shape, in other words, the workpiece is deformed between two die halves which carry the impression of the desired final shape and it usually uses for smaller components. The suitable forging temperature improves plastic flow characteristics and reduces the forces on the forging tools (http://www.forging.org/Design/page1.html, n.d.).

- $\quad$ Ring rolling forging

Ring rolling first scientific developments were made in the 20th century (Weber, 1959). The process begins with a "donut" shaped preform, which is made by upsetting and piercing operations. The preform is placed over the idler roll in a ring rolling mill. The idler roll is moved toward a drive roll, which rotates to reduce the wall and increase the diameter, while forming the desired shape (http://www.forging.org/Design/page1.html, n.d.). Long process times and high process cost are disadvantages of these methods (Berns H, 1993) while it is perfect method for microstructure by continuous local plastic deformation (Dongsheng Qian, 2013). Ring rolling process which allows a flexible near-net-shape forming of both hot and cold rings is presented by Allwood et al (Allwood J, 2007).

- Cold forging

Cold forging has numerous influence on manufacturing process in huge quantities, parts with surface quality and high dimensional accuracy in addition to high strength because of work hardening. Material costs and machining resources can be saved by this type of net-shape production (T. Kroiß, 2013).

- Warm forging

Warm forging is a modification of the cold forging process where the workpiece is heated to a temperature significantly below the typical hot forging temperature (http://www.forging.org/Design/page1.html, n.d.).

\subsection{Bending Structure}

Bending in sheet metal forming explain as the straining of the metal around a straight axis. A neutral axis plane exists for the sheet metal around which the top section of the material may be stretched during bending while the lowest part become smaller by compressing. Usually in conventional sheet metal working, bending operation is depending on bending process that may use wipe dies, punches, rolls, the downward movement of the bending tools for creating edge bending, U-bending, V-bending, etc.

Micro-bending process: Microbending (bends too small to be seen with the naked eye) happen when pressure is applied to the surface of an optical fiber (Watson, 2011). The use of bending process in manufacture of micro sheet metal products mainly is for electronics products and MEMS (micro electromechanical manufacturing 
systems), as industrialization of regular requirements such as producing 3D profiles/sections (H.-W. Jeong, 2003). Totally, for creating micro products can mention to the key parameters of the bend angle, bend radius, bend allowance, length of bend, etc., in some stages of bending process.

Controvertibly, the plan and design of typical micro sheet metal forming process specially for bending procedure must be done size-dependent material behavior to fulfil accuracy requirements. One of the common problems in bending of micro-scale sheet metal is to stop the changed appearance of the sheet and controlling springback-related issues, in the Figure 4. This situation often happens when micro-components with shortened structure or bending/cutting process are produced while they still have a progressive die-stamping/forming pattern. The parts from errors caused by the springback may replace for correct designing the die and the bending characteristics, or introducing additional process. Due to the fact that the parameters of micro-parts, micro-assembly is hard to handle, therefore making spring back or elimination of them is more crucial than in the macro scale. Thus, bending test helps to show the result of these size effects on springback behavior of metal (Jenn-Terng Gau, 2007). Stretch bending, overbending, bottoming and rebending are the methods usually utilized to remove the errors resulted from the springback in conventional sheet metal forming. Another indispensable factor can influence on reducing springback is the changing of product design and original structure of production because it allows to obviate occurrence of springback before the step of production.

It may be difficult to use some of these various methods in micro-sheet forming, for instance difficulty in adding additional tools, limited cost, difficulty of access to the geometric small areas, forming parts in the limited tooling space and forming special material. As a case in points, the behavior of bending process in metal foil are basically affect by two opposing size reason (Alexander Diehl, 2010): First is a reduction in material strength result from the increasing share of surface grains on the overall volume (MF, 1970). Next reason is the declining foil density at the most continual permissible strain led to the increasing thickness of geometric-dependent dislocation because of larger strain gradients (Fleck NA, 1977), for avoiding difficulties in handling parts/microcomponents and in the fabrication of microtooling, non-contact processing methods such as laser-assisted bending may be suggested to achieve accurate bend geometries (N, 2003); for example, in several years ago Vollertsen and Kals investigated the micro sheet metal forming in technical aspect of laser bending and air bending for thickness of down 0.1mm (M. Geiger, 1996) (Kals, 1998).

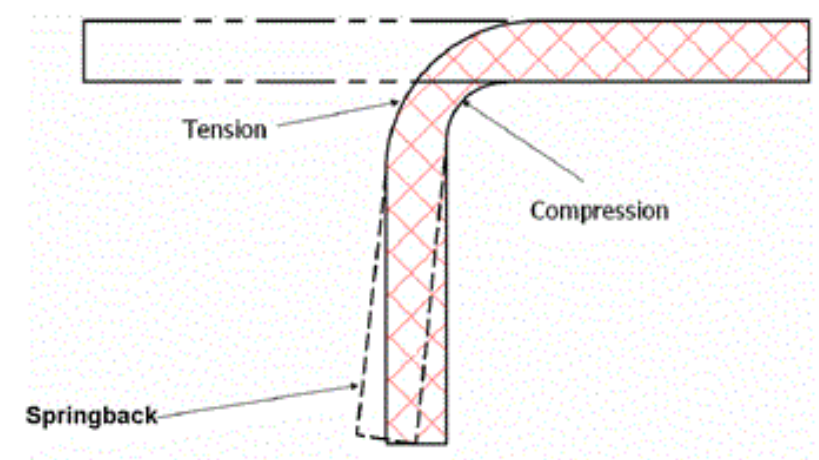

Figure 4. Phenomenon of springback and bending process (Hedrick, 2007)

\subsection{Drawing Structure}

Drawing is one of the main sheet metal-forming processes that utilize to make totally complex-curved, hollow-shaped sheet parts, or box-shaped, cup-shaped (R.K.Jain, 2006). As a matter of fact, drawing sheet metal is a part of metal science for setting correct balance between breaking to reach a successful part and wrinkles. Drawing process totally is divided to the two types: first is sheet metal drawing that includes plastic deformation in curved axis and second is tube, bar, wire drawing that involves to decline in diameter of a die and growth of its length. Actually, impressive drawing during the process depends on a number of reasons, these involve the result of the changing blank holder force to stop wrinkles without excessively delaying metal flow, the choose of suitable material for both blank and die to have adequate coefficient of friction, formability of the material being drawn, limited punch force in drawing operation to lower worth than that which will fracture the shell wall (A.Purushotham, 2013).The information about the geometric change and stiffness attributes is vital due to the purpose of the process limits of the deep drawing. Furthermore, this knowledge is necessary for investigation of 
stiffness decrease for real components in initial structured sheet metal (V. Malikov, 2013).

Micro-deep drawing: The process of micro deep drawing are explained to a sheet that place on a die as well as sufficient amount of pressure apply to a blank holder. With the move downward of the punch, the sheet push into the die and the areas formed after drawing (Feng Gong, 2011). The first approach of micro deep drawing parts for deeper understanding according to the theory of similarity is downscaling the factors of mechanical macro deep drawing (H. Pawelski, 2000).Normally, deep drawing process may combine some operations such as compression, shearing, bending, unbending and stretching that is associated with geometric part to be manufactured. Thus deep drawing is a more complex process than bending or cutting/shearing process, but the process of deep drawing is quite similar to cutting operation.

Drawing ratio, diameter of the punch/ the blank = DR, is a major problem of micro-deep drawing due to DR values in limited space, which normally creates limitation of tooling arrangement and controlling conditions. This limiting drawing ratio (LDR) generally is associated with micro-structure and sheet material thickness and also the method of changing blanks and formed cups with the sheet metal strips in layout design of stamping/forming; in fact, it is performed because of the difficulties are related to handling these small item. Experimental investigation of micro deep drawing demonstrate the basic issue of limit drawing ratio that stem from problems of size-effects; in other words, this situation often occur when friction coefficient in micro deep drawing that resulted from applied pressure. In micro deep drawing process due to size-effect and its new concerns, it is compared to macro deep drawing while experiments have shown under the same forming conditions the friction coefficient in micro deep drawing is greater than that in macro deep drawing (F. Vollertsen H. S., 2007; F. Vollertsen Z. H., 2004; Y. Saotome, 2001; M.W. Fu, 2013). One of the most processes that produce significant friction in micro deep drawing is strip drawing in Figure 5, when the punch start to move into female die, between the blank holder and the sheet, and between female die and the sheet, friction occurs (Chunju Wang B. G., 2013). Even though it has numerous friction in process, the total goal of strip drawing can be simply to improve dimensional tolerances, to improve surface, or to work hardly and so rise the strength of the product (H.L. Costa, 2009).Recent research have indicated, most of the results in this challenge have been investigated by powerful tool Finite Element (FE) simulation and it is beneficial to forecast the performance of processes in advance, but FE-programs don't consider size effect. Therefore, mathematical model for implementation and size effect is necessary (A. Messner, 1994).

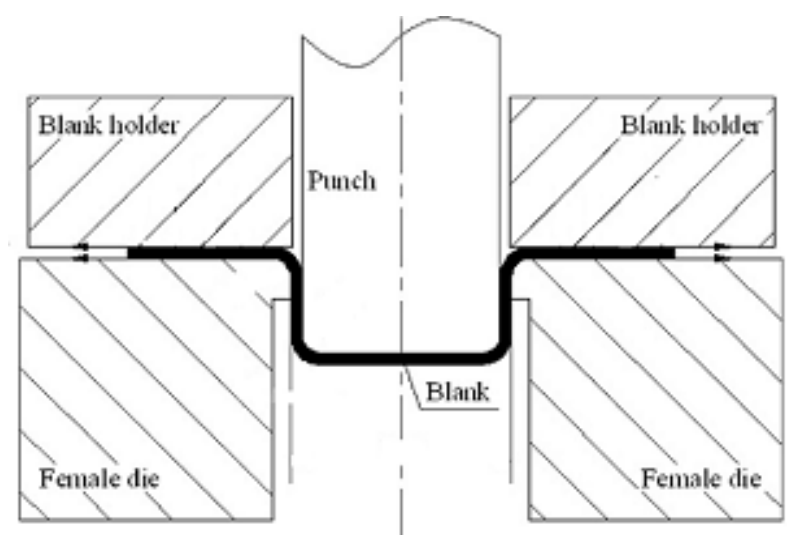

Figure 5. performance of deep drawing and schematic of strip drawing (Chunju Wang B. G., 2013)

Redrawing is normally essential for micro products, because of limited accomplishment of a possible reduction value of a cup. Redrawing operation can demonstrate ironing and annealing process is feasible for miniature cups (Yi Qin A. B., 2010). When micro products are encountered with limiting drawing ratio, redrawing process has to be employed for improving this problem; that is, If the first redrawing cannot manufacture a deep cup, second redraw is worked, and so on (You-Min Huang, 1999). Figure 6 indicates a redrawing process. As paper demonstrates the redrawn product is performed on the inner fringe b0a0. At the same time during this process, the material on $\mathrm{b}^{\mathrm{a}} \mathrm{a}$ at a sure height on the partition of the pre-drawn cup has to reach and pass through the inner fringe $\mathrm{b} 0 \mathrm{a} 0$. 


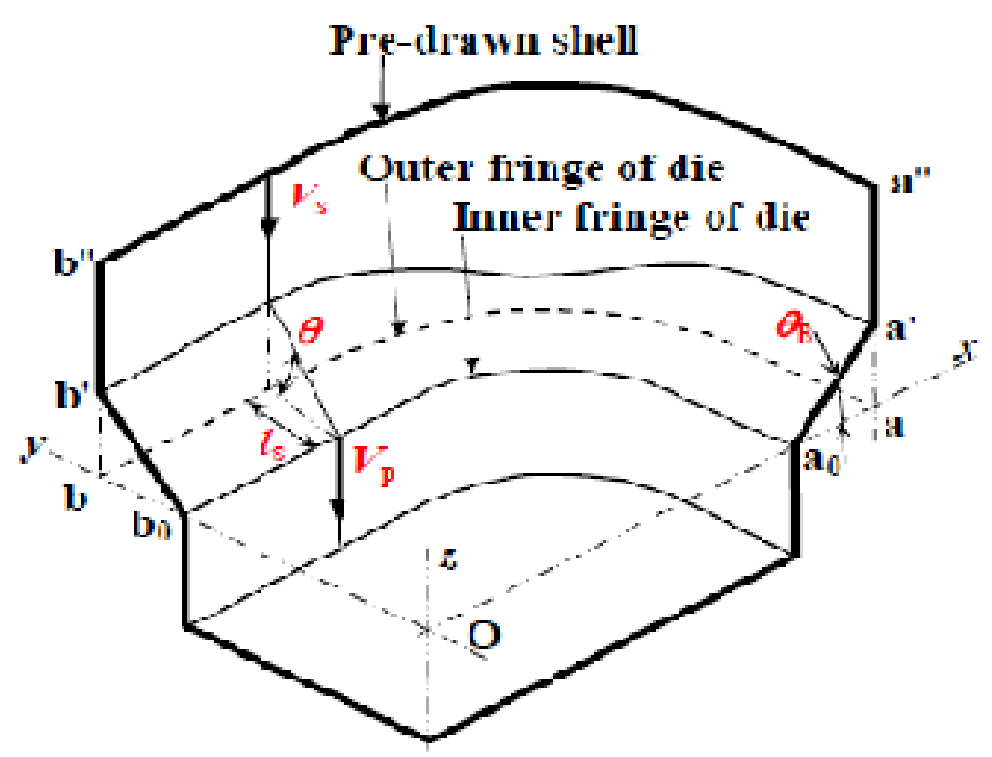

Figure 6. Redrawing of rectangular cup (Isobe, 2010)

Obviously, the wall thickness at corners of cups are so large and design of redrawing dies for preventing errors and trial require experiences of experts. So any shape of pre-drawn specially for cups are calculated.

\section{Conclision}

Incontrovertibly, the researches of micro-manufacturing have been produced substantial results in processes, material and equipment during 2000 up to now. In micro-components, the high-volume production should be prominent purpose for designing micro-manufacturing. As discussed in this paper, further analysis is necessary for improving micro-forming method particularly deep drawing and bending process and also more fundamental researches are required on interaction between handling tools and materials. In future, micro-manufacturing will be better connection between Nano-manufacturing and macro-manufacturing due to progression of technology in machining and handling.

\section{References}

A. Messner, U. E. (1994). Size effect in the FE-simulation of micro-forming processes. Materials Processing Technology, 371-376.

A.Purushotham. (2013). Simulation studies on Deep Drawing Process for the Evaluation of stresses and strain. Computational Engineering Research, 3, 40-47.

Akhtar Razul Razali, Y. Q. (2013). A Review on Micro-manufacturing, Micro-forming and their Key. Procedia Engineering, 53, 665-672.

Aldo Attanasio, M. G. (2013). Influence of Material Microstructures in Micromilling of Ti6Al4V Alloy. materials, 4268-4283.

Alexander Diehl, U. E. (2010). Size effects in bending processes applied to metal foils. Production Engineering Resource Development, 4, 47-56.

Allwood J, K. R. (2007). The technical and commercial potential of an incremental. CIRP Annals Manufacturing technology, 54, 233-236.

B.T. Cheok, A. N. (1998). Trends and developments in the automation of design. Materials Processing Technology, 75, 240-252.

Berns H, N. C. (1993). Herstellung und eigenschaften thermischer spritzschichten mit gradierter structur. Härterei-technische Mitteilungen, 48, 20-24.

Byung-Yun Joo, S.-H. R.-I. (2005). Micro-hole fabrication by mechanical punching process. Materials Processing Technology, 170(3), 593-601.

Chunju Wang, B. G. (2013). Tribological behaviors of DLC film deposited on female die used in strip drawing. 
Materials Processing Technology, 323-329.

Chunju Wang, B. G. (2013). Tribological behaviors of DLC film deposited on female die used in strip drawing. Materials Processing Technology.

D. Jahns, T. K. (2013). Laser trepanning of stainless steel. Physics Procedia, 41, 630 - 635.

Dongsheng Qian, Z. Z. (2013). An advanced manufacturing method for thick-wall and deep-groove ring-Combined ring rolling. Materials Processing Technology, 213, 1258- 1267.

F. Vollertsen, H. S. (2007). SHEET METAL MICRO FORMING. 6th international conference on industrial tools and material processing technologies. bled, slovenia.

F. Vollertsen, Z. H. (2004). State of the art in micro forming and investigations into micro deep drawing. Materials Processing Technology, 70-79.

F.H. Osman. (1995). Preform Design for Forging Rotationally Symmetric Parts. CIRP Annals. Manufacturing Technology, 44(1), 227-230.

Feng Gong, B. G. (2011). Micro deep drawing of micro cups by using DLC film coated blank holders and dies. Diamond \& Related Materials, 196-200.

FIA. (1996). Forging Industry Vision of the Future. Forging Industry Association.

Fleck NA, H. J. (1977). Strain gradient plasticity. Advances in Applied Mechanics, 33, 295-361.

Gwo-Lianq Chern, Y. C. (2006). Study on vibration-EDM and mass punching of micro-holes. Materials Processing Technology, 180(1-3), 151-160.

Gwo-Lianq Chern, Y.-J. E.-F. (2006). Development of a micro-punching machine and study on the influence of vibration machining in micro-EDM. Materials Processing Technology, 180(1-3), 102-109.

H. Pawelski, O. P. (2000). Technische Plastomechanik . Verlag Stahleisen,.

H.L. Costa, I. H. (2009). Effects of die surface patterning on lubrication in strip drawing. materials processing technology, 1175-1180.

H.-W. Jeong, S. H. (2003). Microforming of three-dimensional microstructures from thinfilm metallic glass. Microelectromechanical systems, 12, 42-52.

Hans Nørgaard Hansen, M. A. (2010). Micromanufacturing Engineering and Technology. In Micro-Mechanical-Assembly. Elsevier.

Isobe, K. (2010). FLASH DESIGN OF DIE SHAPES FOR REDRAWING RECTANGULAR CUPS. Material Forming, 3, 85- 88 .

J. Cecil, D. P. (2007). Assembly and manipulation of micro devices-A state of the art survey. Robotics and Computer-Integrated Manufacturing, 23, 580-588.

J. Chae, S. P. (2006). Investigation of micro-cutting operations. Machine Tools \& Manufacture, 313-332.

Jain, R. K. (2006). Production technology. Khanna publishers.

Jenn-Terng Gau, C. P. (2007). Springback behavior of brass in micro sheet forming. Materials Processing Technology, 191, 7-10.

Jie Xu, B. G. (2011). Size effects in micro blanking of metal foil with miniaturization. Advanced manufacturing technology, 56(5-8), 515-522.

Joseph Domblesky, F. K. (2006). Welded preforms for forging. Materials Processing Technology, 171, 141-149.

K.P. Rajurkar, G. L. (2006). Micro and Nano Machining by Electro-Physical and Chemical Processes. CIRP Annals - Manufacturing Technology, 55(2), 643-666.

Kalpakjian S, S. S. (2006). Manufacturing Engineering and Technology.

Kals, R. (1998). Fundamentals on the Miniaturization of Sheet Metal Working process. PHD thesis.

M. Geiger, F. V. (1996). Fundamentals on the manufacturing of sheet metal microparts. Advanced Performance Materials, 3, 123-151.

M.W. Fu, B. Y. (2013). Experimental and simulation studies of micro blanking and deep drawing compound process using copper sheet. Materials Processing Technology, 101-110.

MF, A. (1970). The deformation of plastically non-homogeneous materials. Philosopical Magazine, 21, 
399-424.

N, M. (2003). Laser micro-bending for precise micro-fabrication of magnetic disk-drive components. Laser Precision Microfabrication, 24-29.

Nagayoshi Kasashima, T. (2012). Laser andelectrochemicalcomplexmachiningofmicro-stentwith on-machine three-dimensionalmeasurement. Optics andLasersinEngineering, 50, 354-358.

Nee, A. (1989). PC-based computer aids in sheet-metal working. Mechanical Working Technology, 19(1), 11-21.

Pandey, D. P. (n.d.). http://paniit.iitd.ac.in/ pmpandey.

Qin, Y. (2006). Micro-forming and miniature manufacturing systems — development needs and perspectives. Materials Processing Technology, 177(1-3), 8-18.

Qin, Y. (2010). Overview of manufacturing. In Micromanufacturing Engineering and Technology. Elsevier.

Renn, J.-C. C.-L. (2004). Development of a Novel Micro-Punching Machine Using Proportional Solenoid. CHINESE SOCIETY OF MECHANICAL ENGINEERS, 89-93.

S. Hinduja, M. K. (2013). Modelling of ECM and EDM processes. CIRP Annals - Manufacturing Technology, 62, 775-797.

T. Kroiß, U. E. (2013). Comprehensive approach for process modeling and optimization in cold forging considering interactions between process, tool and press. Materials Processing Technology, 213, 1118 1127.

T. Masuzawa. (2000). State of the Art of Micromachining. Manufacturing Technology, 49(2), 473-488.

Tatsuhiko Aizawa, E. I. (2007). Development of nano-columnar carbon coating for dry micro-stamping. Surface \& Coatings Technology, 202, 1177-1181.

Toyoaki Matsuura, M. K. (2006). Study on metallic bipolar plate for proton exchange membrane fuel cell. Power Sources, 161, 74-78.

Tsung-Chia Chen, J.-M. Y. (2013). Fabrication of micro-channel arrays on thin stainless steel sheets for proton exchange membrane fuel cells using micro-stamping technology. Advanced Manufactruring Technology, 64, $1365-1372$.

V. Malikov, R. O. (2013). Experimental study of the change of stiffness properties during deep drawing of structured sheet metal. Materials Processing Technology, 1811- 1817.

Watson, V. (2011). Microbending \& Macrobending Power Losses in Optical Fibres.

Weber, K. (1959). Ring rolling and the construction of ring mills. Stahl und Eisen, 79, 1912-1923.

X Liu, M. J. (2004). Cutting mechanisms and their Influence on dynamic forces, vibrations and stability in micro-endmilling. Mechanical Engineering Congress and Exposition, 13-20.

Xichun Luoa, K. C. (2005). Design of ultraprecision machine tools with applications to manufacture of miniature and micro components. Materials processeing technology, 167(2-3), 515-528.

Y. Saotome, K. Y. (2001). Microdeep drawability of very thin sheet steels. Materials Processing Technology, 641-647.

Yi Qin, A. B. (2010). Forming of Micro-Sheet-micro components. In micro manufacturing (p. chapter 8).

Yi Qin, A. B. (2010). Micro-manufacturing: research, technology outcomes and development issues. Advanced Manufacturing Systems and Technology, 821-837.

You-Min Huang, C.-L. L. (1999). An elasto-plastic finite-element analysis of the metal sheet redrawing process. Materials Processing Technology, 331-338.

\section{Copyrights}

Copyright for this article is retained by the author(s), with first publication rights granted to the journal.

This is an open-access article distributed under the terms and conditions of the Creative Commons Attribution license (http://creativecommons.org/licenses/by/3.0/). 